\title{
Numerical simulation of thermal performance of different frost-resisting measures for the tunnel lining in cold region
}

\author{
Chengjin $\mathrm{Ma}^{1,}$ a , Runlin Yang ${ }^{1, \mathrm{~b}}$ and Shuai Zhang ${ }^{1, \mathrm{c}}$ \\ ${ }^{1}$ Department of Civil Engineering, School of Civil and Resource Engineering, University of Science \\ and Technology Beijing, Beijing 100083, China \\ amcjin13@163.com, brlyang@ustb.edu.cn, c2297233372@qq.com
}

Keywords: tunnel; lining; temperature field; thermal performance

Abstract. Frost-resisting problem is important for the tunnel in cold region, and thus some thermal protective measure are necessary in order to avoid potential frost. With the development of land transport, tunnels plays an important role in the improvement of land transportation, so it is urgent to prevent the freezing and thawing of tunnel in cold region. In this paper, the temperature field of Jinzhangzi tunnel is chosen as a target project, and corresponding three protective measure are taken into account. There are four cases are considered respectively. Including the unprotected, the active heating system, passive thermal insulation system and hybrid thermal protective system. Especially, the hybrid thermal protective system maybe the cost efficient.

\section{Introduction}

In the seasonally frozen soil area, the factors causing the tunnel frost damage are not only the load, but also the freeze-thaw cycle. Because of the low temperature effect of cold environment to the lining of the tunnel. There may be a series of frost damage phenomena in the tunnel include the cracks of lining, water seepage, the hanging ice column and icy or slippery of the roadway. Hence, taking the thermal protective measure is often necessary for the tunnel in cold region.

In recent years, the problem of frost damages of the tunnel has been paid more and more attention. There are three protective measure are considered for Jinzhangzi tunnel include the active heating system, passive thermal insulation system and hybrid thermal protective system. Consequently, four cases need be considered, i.e. the unprotected, the active heating system, passive thermal insulation system and hybrid thermal protective system.

\section{Engineering background and thermal protective measures}

Engineering background. The Jinzhangzi tunnel belongs to the National Highway 101 line in Pingquan county, Chengde city. The main surrounding rock is so-called Anshan Rock. The fracture of the rock is obvious, and the fissure water is rich. The monthly lowest temperature can be far below minus 20 degree centigrade in January every year. Therefore, the target tunnel must take the thermal protective measures.

The length of the tunnel is $480 \mathrm{~m}$. The primary lining adopts the $\mathrm{C} 25$ reinforced concrete, and its thickness is $8 \mathrm{~cm}$. The secondary lining is the $\mathrm{C} 25$ reinforced concrete, and its thickness is $30 \mathrm{~cm}$. The tunnel model dimension is shown in Fig.1.

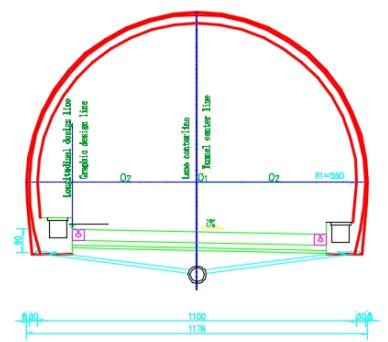

Fig. 1 Dimension of the target tunnel 
Working principles of thermal protective systems. The active heating system assumes the electrical heating belt system which are laid on the concrete lining surface. The electrical group system is a radiant heating system, which converts electrical energy into heat energy through a heating cable and then transmits it to the lining structure to achieve the desired thermal performance effect. At present, there are two main types of heating cable in the market: constant power and self-limiting type.

Generally the constant-power heating cable is used in the industrial and civil engineering. In the process of numerical simulation, it is assumed that the constant power type heating cable is used, and the line power is $10 \mathrm{w} / \mathrm{m}$ and the laying spacing is $10 \mathrm{~cm}$. The model diagram is shown in Fig. 2 .

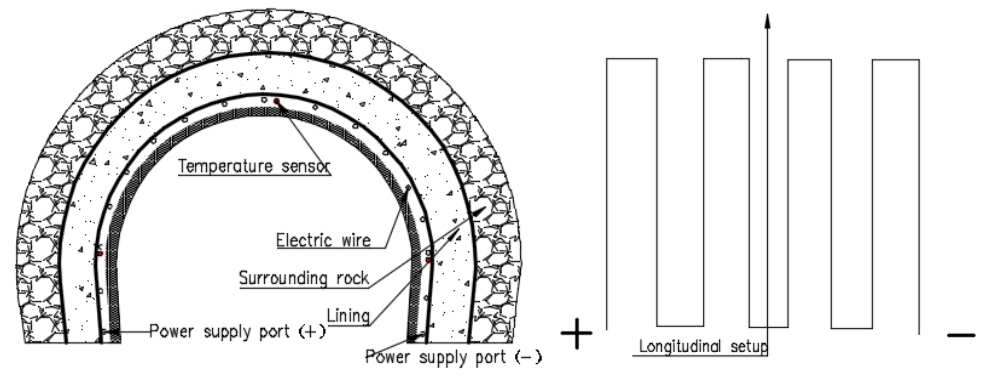

Fig. 2 Diagram of active thermal insulation model diagram

Passive thermal insulation system need lay the insulation layer on surface of the concrete lining. Its thermal performance depends on the thermal physical parameter. Well, the temperature of lining is higher, the active heating system will stop working and the passive thermal insulation system works normally. Once the temperature of lining is lower, both of them work in order to provide more heat energy for the concrete lining, as shown in Fig.3.

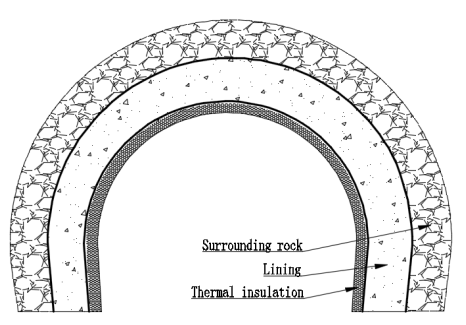

Fig. 3 Diagram of passive thermal insulation model.

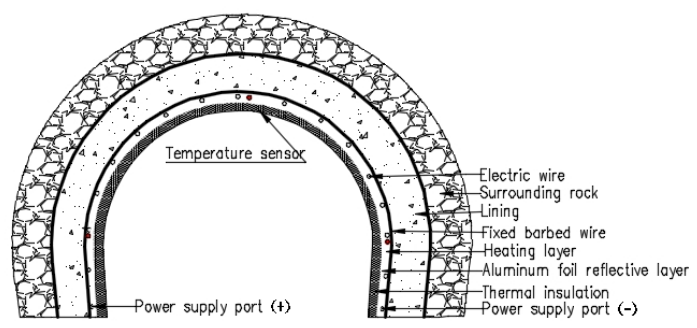

Fig. 4 Diagram of hybrid thermal insulation model

The hybrid thermal protective system takes advantage of the active heating system and thermal insulation fulling, as shown in Fig.4.

\section{Computational model parameters and boundary conditions}

Computational model. The temperature inside of the tunnel is affected by the atmospheric temperature. The environment can exert an impact influence upon temperature of the concrete lining, especially, the temperature of the entrance or the exit of the tunnel is lowest, therefore a 10m long part from the entrance of the tunnel is taken as the computational model. Its dimensions are simplified as follows: the width is $11 \mathrm{~m}$, the height is $8 \mathrm{~m}$, and the thickness of the lining is $38 \mathrm{~cm}$. Obviously, the initial temperature which apply to lining surface of the tunnel is the same as environmental temperature, and correspond thermal simulation are carried out.. The finite element computational model is shown in Figure 5, Figure 6, Figure 7 and Figure 8. 


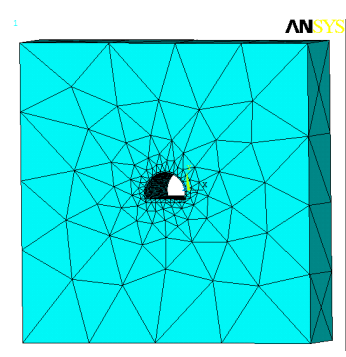

Fig. 5 Calculation model of tunnel.

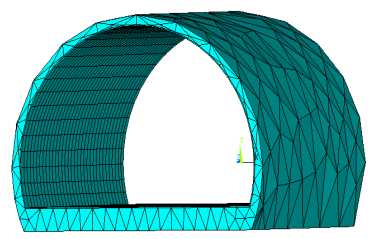

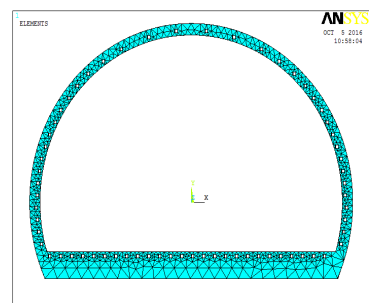

Fig. 6 Calculation model of active heating measures for electric belts

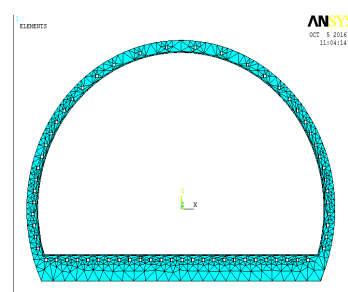

Fig. 7 Calculation model of passive insulation.

Fig. 8 Calculation model of hybrid thermal insulating

Computational parameters. This paper adopts the polyethylene insulation material, the thermal conductivity is $0.032 \mathrm{w} / \mathrm{m} \cdot{ }^{\circ}$ Cand the laying thickness is $4 \mathrm{~cm}$.

Thermal performance of the tunnel structure involves the thermodynamic properties of the lining and the surrounding rock, which need to be considered from two angles. From the angle of material, it is mainly related to the thermal physical parameters of the lining and the surrounding rock material, including thermal conductivity, specific heat and density, and from the angle of structure, it is influenced by the porosity and water content of the structure. For the sake of simplicity, it is assumed that the tunnel structure is composed of each layer is isotropic, and the material calculation model is considered by linear elasticity, and the thermal physical parameters of the concrete lining and the surrounding rock are given in table 1 respectively.

\begin{tabular}{lccc}
\multicolumn{4}{c}{ Table 1 Thermal Physical parameters } \\
\hline Materials & $\begin{array}{l}\text { Coefficient of thermal } \\
\text { conductivity } /\left(\mathrm{W} /\left(\mathrm{m} \cdot{ }^{\circ} \mathrm{C}\right)\right)\end{array}$ & $\begin{array}{l}\text { Specific heat } \\
/\left(\mathrm{kJ} /\left(\mathrm{kg} \cdot{ }^{\circ} \mathrm{C}\right)\right)\end{array}$ & Density $/\left(\mathrm{kg} \cdot \mathrm{m}^{-3}\right)$ \\
\hline Concrete & 1.74 & 0.92 & 2500 \\
\hline Surrounding rock & 3.49 & 0.92 & 2800 \\
\hline
\end{tabular}

Boundary conditions of the model. The heating belt works under constant-power, and the thermal flux can be converted according to the line power (1).

$$
q_{s}=\frac{q_{1}}{3.14 d}
$$

Formula: $q_{s}$----- Thermal flux on cable surface $\mathrm{W} / \mathrm{m}^{2}$;

$q_{1}$---- Line power rating $\mathrm{W} / \mathrm{m}$;

d ----- Diameter of the cable $\mathrm{m}$.

According to the local statistic data, the concrete lining surface chooses the minus 20 degree centigrade as the initial temperature. The convective heat transfer coefficient is $15 \mathrm{w} / \mathrm{m}^{2} \cdot{ }^{\circ} \mathrm{C}$ between the cold air and the surface of tunnel lining. The temperature of deepest is considered constant and the corresponding value is select as $3{ }^{\circ} \mathrm{C}$.

\section{Numerical analysis of results in various working conditions under temperature and load}

Initial temperature of the model. The temperature field of tunnel lining and the surrounding rock structure is related to the initial temperature field, and it is very important to determine correctly the 
initial temperature of the structure. Steady state thermal analysis can be used to determine the steady temperature field of the tunnel lining and the surrounding rock at low temperature as shown in Fig. 9. Fig. 9 is also the temperature field distribution of the tunnel lining and surrounding rock structure without heating preservation measures.

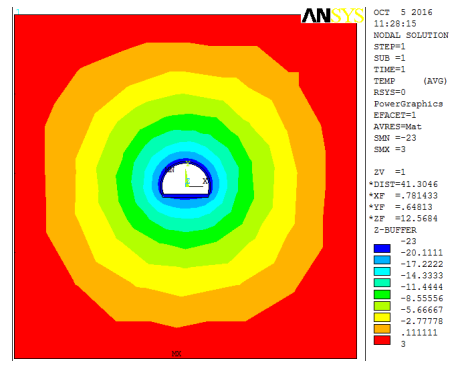

Fig. 9 The initial temperature field distribution of the tunnel and its surrounding rock

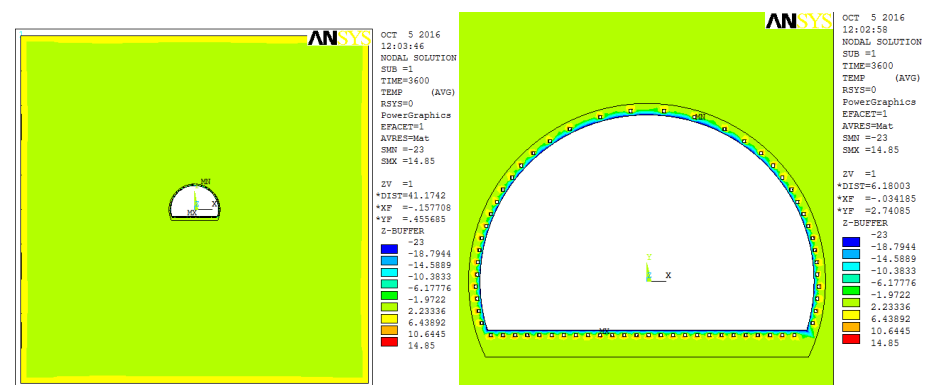

Fig.10 Temperature field distribution chart under active heating measures

Fig. 10 is the temperature field distribution cloud under the active heating measure. Corresponding to the passive thermal insulation system, the temperature field distribution is given in Fig.11. Fig. 12 is the temperature field distribution of hybrid thermal protective system.

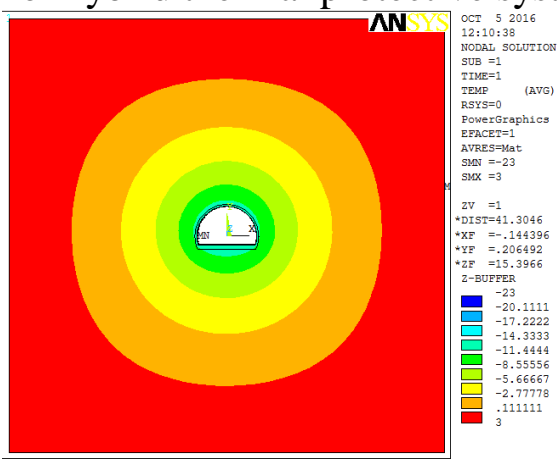

Fig. 11 The temperature field distribution cloud under the passive thermal insulation measure

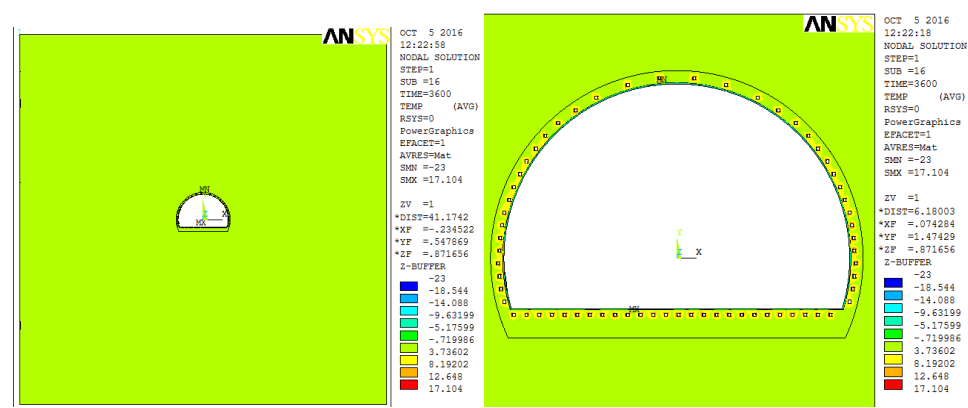

Fig. 12 Temperature field distribution chart under hybrid thermal protective measures

Analysis and comparison of temperature field data. It may combine the features of both the active heating system, the passive thermal insulation system in order to analyze the effect of different thermal protective measures. As the following in Figure 13. 


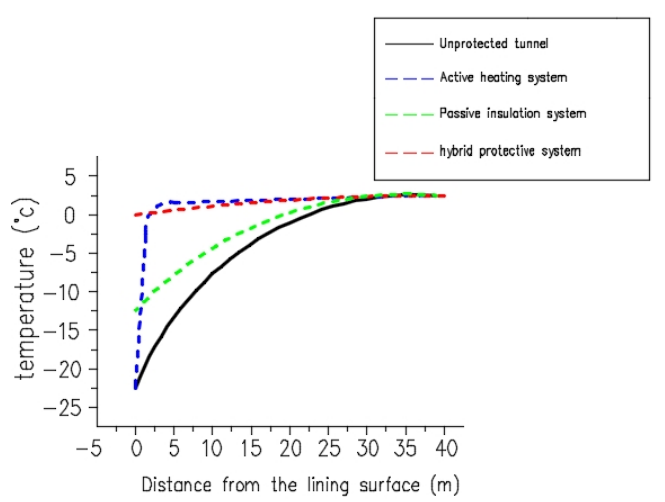

Fig. 13 Comparison of thermal effect at different position

The results of the data analysis can be concluded as follows: (1) If the tunnel is unprotected, and thus the temperature on the tunnel surface is basically close to the atmosphere. The farther observing point from the lining surface, the higher corresponding temperature is.

(2) With change of the longitudinal position of the tunnel, the corresponding temperature maybe different. The farther cross-section of the tunnel from the entrance or the exit of the tunnel, the less influence corresponding temperature is.

(3)Among three thermal protective system, the active heating system is the best in raise the temperature of the tunnel surface, the passive insulation system is the worst and the hybrid thermal protective system is the most cost performance.

\section{Conclusions}

According to the numerical results, the atmosphere has direct influence on the temperature of the tunnel lining and the surrounding rock in a certain range of the deep. If there is the pore water inside the rock, the frost phenomena will occur continuously in winter. Therefore, it must be considered prevent the tunnel from the frost damage. Generally speaking, the hybrid thermal protective system may be the best approach to solve the problem.

\section{References}

[1] Huijun Jin,Shuxun Li, Shaoling Wang, Lin Zhao. Effects of climate change on the environment of permafrost and cold regions in China [J]. Geography Journal, 2000, 02:161-173.

[2] Guanglong Zhang . Study on heat preservation and frost-proof test and numerical simulation of tunnel in cold zone based on electric heating [D]. Chang'an University, 2012

[3] Yuanming Lai,Wenbing Yu, Ziwang Wu, He Ping, Mengxi Zhang . Analytic solution of temperature field of circular cross section tunnel in cold region [J]. Glacial permafrost, 2001, 02:126-130.

[4] Yanling Luo,Ping Cao. Development and application of self-control temperature heating cable [J]. Chemical production and Technology, 2000, 01:20-22+3.

[5] Caihua Sun. Numerical analysis of heat transfer by finite element method [J]. Journal of Qinghai Normal University (natural Science Edition), 2013, 01:31-33+44.

[6] Gang Deng. Design of tunnel anti-frost damage in high altitude cold zone [D]. Southwest Jiaotong University, 2012

[7] Haiqin Wu. Study on the technology of heating cable for melting snow ice in pavement [D]. Beijing University of Technology, 2005 